\title{
IMPROVING PERFORMANCE OF A SEED DRILL FOR DEPOSITING MINERAL FERTILIZER

\author{
El-Hanfy, E. H.
} \\ Inst. For Efficient Productivity, Zagazig Univ. Egypt.
}

\begin{abstract}
In Egypt the fertilizer in wheat are generally applied as broadcast before and during seeding. This is wasteful method of fertilizer application as only $15-20 \%$ of applied fertilizer is utilize by wheat crop. The present investigation aim to modify seed drill to placement fertilizer at desired depth sub seeds. The modified seed drill provided with fertilizer opener fixed between every two seed furrow opener in order to seed and fertilizer drilling at different depths and covering the seed and fertilizer simultaneously in a single operation. During the field testing, observations such as depth of seed and fertilizer placement, vertical distance between seed and fertilizer, germination capacity, plant emergence and population plant stand seed and fertilizer rates are recorded. The modified seed drill could be used for seeding a variety of crop. Which could result in $40 \%$ and $33 \%$ saving of Phosphates and Nitrogen fertilizer respectively also increased plant population by $30 \%$ and $14 \%$ compared with seeding and applied fertilizer by seed drill and seeding by seed drill and broadcast fertilize.
\end{abstract}

\section{INTRODUCTION}

One of the major problems facing crop production in Egypt as well as other parts of world is the appropriate fertilization including program and system of addition. In Egypt mineral fertilizer (Nitrogen, potassium and calcium fertilizer) are generally applied as broadcast. The drawbacks with broadcast application are, stimulate weed growth and fertilizer may come in contact with a large volume of soil and are likely to be fixed, there for, the crop does not derive full benefit of fertilizer, finally for application of phosphoric fertilizer as phosphates are less mobile. Broadcast application will result in unavailability to roots. Consequently as all the three nutrients are applied at the time of sowing or planting, it is a good practice to apply the fertilizer as placement, to decrease fertilizer looser by drainage water and increased the total nutrients in soil profile. The advantages of fertilizer placement are, stimulates early growth of seedlings, early root development will be rapid and extensive and plant growth will be stimulated. A placement fertilizer by seed cum fertilizer at different depths sub seed level can affect the availability of nutrient to the germination and led to encourage its emergence, that for best emergence results. The fertilizer furrow. Openers should be designed to but fertilizer below the seed level, press the fertilizer into the compacted soil and cover seed and fertilizer to the proper depth with loose soil to minimize crusting and promote easy emergence.

Hazarila (2008) stated that in currently seed-fertilizer drill, the delivery system, seeds and fertilizer fall together at the same level /surface. Due to this seed get damage from localized concentration of fertilizer during germination. The fertilizer is also not utilizing by the crop roots efficiently. This increase the total need of fertilizer for a farm. 
Abdul-Shakoor et al. (1990) mentioned that in order to mechanize crop sowing operation, a suitable drill is vital as it places the seed and fertilizer in the zone of adequate moisture and desired depth. The proper placement of seed and application of basal dose of fertilizer can help in achieving better yields witch are directly affected by healthy germination crop stand and plant population.

Subudhi et al. (1997) tested different seed drills (seed drill, seed-cum fertilizer drill) and tow other conventional seeding practices (seeding behind the plow and broadcasting) for upland rice during three cultivation seasons, they noticed that the highest rice grain yield was observed using seed cum fertilizers and the broadcasting had a lowest yield.

Gupta et al. (2004) development and testing a seed cum fertilizer drilling in order to furrow opening, seed and fertilizer drilling and covering of seed simultaneously in single operation. The machine could be used for sowing different variety of crops which could result in 20-30 percent savings of precious seed and fertilizers. Uniform seed placement without clusters and controlled seed and fertilizer rates.

Ahmed et al. (2004) stated that in Pakistan, Phosphate fertilizer in wheat is conventionally applied by broadcast method before sowing crop. This is a wasteful method of fertilizer application (15-25\%) of the applied phosphate is utilized by wheat crop. They also revealed that currently seed cum fertilizer drill place fertilizer either too far from the seed or in direct contact with it. In the former case, fertilizer use efficiency is hampered and in latter situation, relatively high rate of ammoniated phosphate fertilizer affects the seed germination and crop yield. They added that to solve mentioned problem the seed cum fertilizer development to place fertilizer $5 \mathrm{~cm}$ away and $5 \mathrm{~cm}$ deeper that the seed. These save $50 \%$ of phosphate fertilizers and get benefit of $10 \%$ more grain yield.

Willatt (1986); Tsegaye and Mullins (1994); Bueno et al. (2002) reported that, As regards soil and climate conditions, openers should achieve several aims, like uniformity of sowing, production of a suitable amount of fine soil aggregate to ensure soil/seed contact, avoidance of seed contact with either fertilizer or crop residues and limitation of furrow compaction, which may obstruct root growth.

Tice and Hendrick (1991); Morrisonet et al. (1996) and Richey (1981) indicated that the produce a "V" shaped furrow with smooth sides, reduce the dispersion of seeds and contribute to the follow of moisture toward them.

Very little work has been done on testing, evaluation and standardization of seed cum fertilizer. As a result no effort has been made for designed/ development of suitable seed cum fertilizer drill. There fore the aim of this investigation to modify currently seed drill to drill seed and fertilizer with covering them in a single operation but at different depths and distance to avoid fertilizers injury to the seed.

\section{MATERIALS AND METHODS}

The TYE type seed drill, of 20 rows, $3 \mathrm{~m}$ width and of two hoppers for seeds and fertilizer, was equipped with the modified wing opener. It has been 
set to deposit fertilizer during seedling operation. The modified seed drill compared with the traditional type that delivers seeds and fertilizers to fall together at the same level/surface. The location of modified furrow opener of fertilizer is lie in between the seeds openers. It is fixed to establishment level and distance between seed and fertilizer furrows in the ground contour and to place fertilizer at adequate depth below level seeds as needed in different crop and with lateral distance from seed furrow of $7.5 \mathrm{~cm}$. The modified fertilizer furrow opener has a straight beam ending with coulter which havening two side wings of $8 \mathrm{~cm}$ wide which angled towards the direction of work formed front opener (Fig. 1).
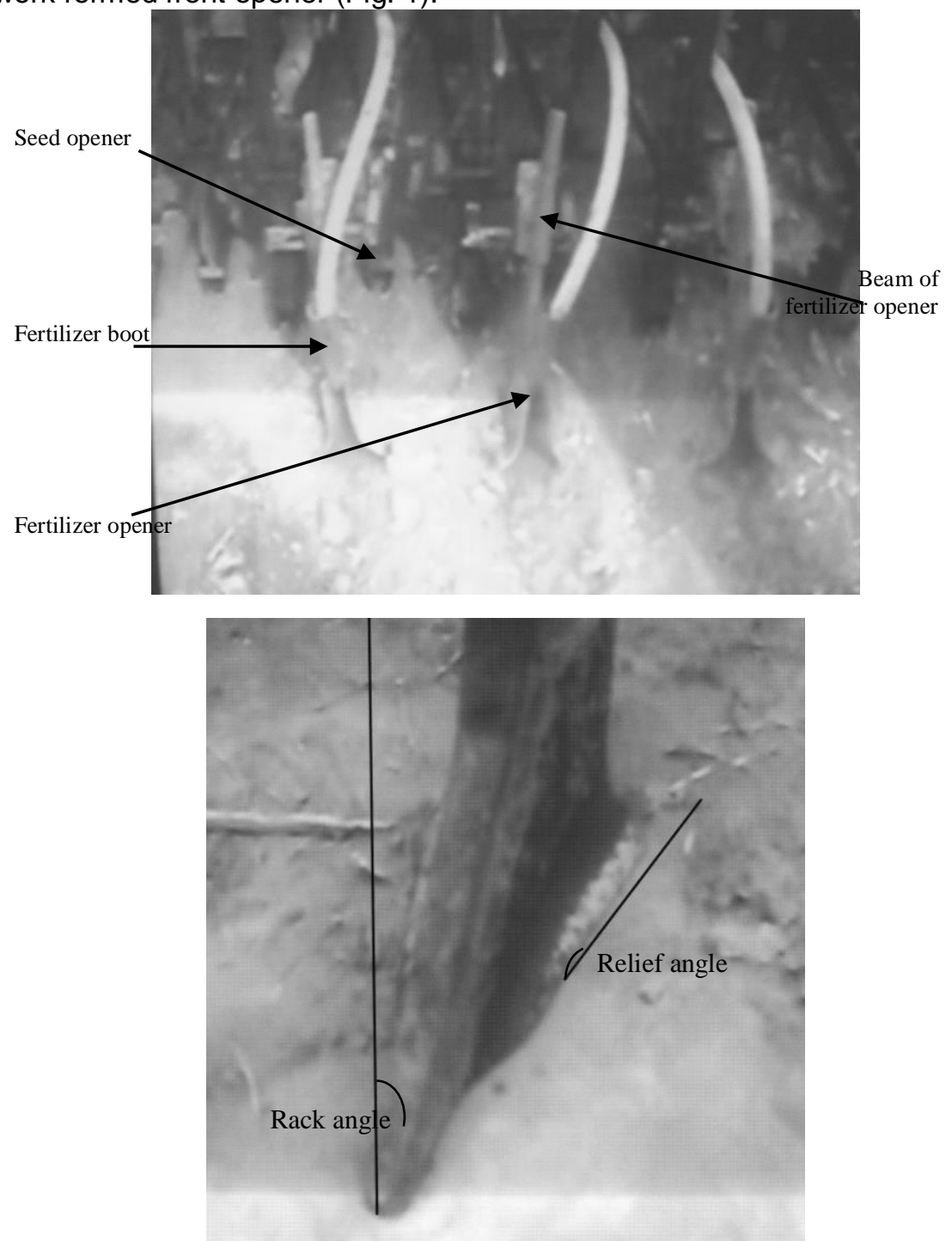

Fig. (1): The modified fertilizer furrow openers 
The rake angle (Fig. 1) is generally kept at around of 20 degree in order to make a slit with minimum soil disturbance. The relief/clearance angle of the furrow opener is normally kept at 5 degree. The relief angle can be further adjusted with the help of the top link to vary fertilizer furrow depth. A $4 \mathrm{~cm}$ wide, $3 \mathrm{~cm}$ thick and $6 \mathrm{~cm}$ stiffener hitching plat is provided at the other end of beam and mounted to the seed furrow opener frame with nuts and bolts. Holes $1.2 \mathrm{~cm}$ in diameter and $2 \mathrm{~cm}$ apart from each other are provide in the beam to vary the vertical distance between fertilizer and seed furrow opener as needed in different crop. One boot is provided behind each furrow opener to receive fertilizer tube (Polly ethylene tube with a minimum diameter of 30 $\mathrm{mm}$ ) from fertilizer metering devise. The furrow opener is adjusted to make 8 $\mathrm{cm}$ width and deep slit. The depth of fertilizer can be adjusted by rising or lowering the shanks of the beam of fertilizer.

The fertilizer furrow shape (with side humps was observed) may be considered as a result of the particular kind of work done by side wings of opener which cut the soil surface and inverted the soil to cover seed in the furrow (Fig. 2). As the angle of inclination of the side walls of the furrow opened by the fertilizer furrow opener is higher than the angle of repose of soil aggregates, therefore after the fertilizer opener leaves the opened furrow and the retarding action of the opener wings was stopped some of the soil located in both sides of the wings will slide down into the fertilizer furrow which gets closed automatically.

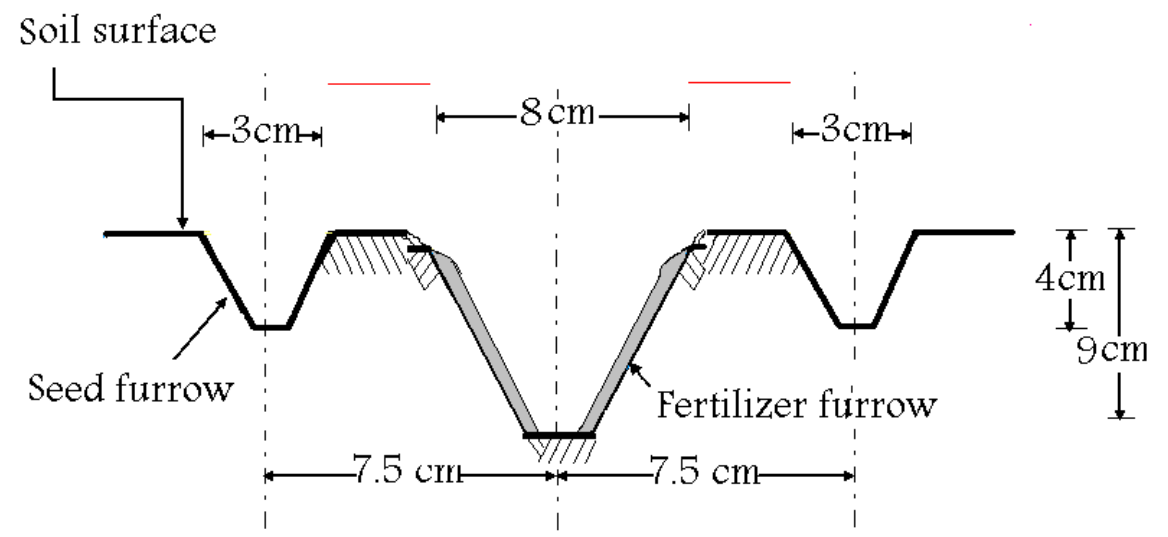

Fig. (2): The fertilizer furrow shape.

The trail was performed in 2008-2009 growing season at agricultural research station in Gemmiza EL-Gharbia Governorate to investigate the effect of placement fertilizer sub-seeds level on emergence and initial plant growth of wheat. Soil mechanical analysis and soil type were shown in Table (1).

Table 1: Soil mechanical analysis and soil type at El-Gemmize

\begin{tabular}{|c|c|c|c|c|c|}
\hline \multicolumn{3}{|c|}{ Sand,\% } & \multirow{2}{*}{ Silt,\% } & Clay,\% & Soil type \\
\hline Coarse,\% & Fine,\% & Total,\% & & & Clay \\
\hline 0.51 & 14.07 & 14.58 & 29.08 & 56.34 & . \\
\hline
\end{tabular}


Gemmiza (9) wheat variety was planted in area about of $1 / 5$ feddan. Twenty seven rectangle plots were marked of $10 \mathrm{~m}$ long and $3 \mathrm{~m}$ width corresponding to 20 furrows. Three sowing method are used namely,

1-Mechanical drilling by a TYE type seed drill with a new fertilizer wing furrow opener placement fertilizer sub seed level $\left(P_{1}\right)$.

2-Mechanical drilling by a traditional TYE type seed drills which placement fertilizer at the same level of seeds $\left(P_{2}\right)$.

3-Mechanical drilling with TYE type seed drill and manual broadcasting fertilizer $\left(P_{3}\right)$.

Mechanical drilling were done at three different operational speed of 3,4 , $5 \mathrm{~km}$. $\left(S_{1}, S_{2}, S_{3}\right)$ respectively. The fertilizer used in this study were, Super phosphate Calcium $\left(\mathrm{P}_{2} \mathrm{O}_{5} 15.5 \%\right)$ as a phosphates fertilizer and Ammonium Sulfate $(20.6 \% \mathrm{~N})$ as nitrogen fertilizer. The fertilizers had the following properties as Abdel-Wahab et al. (1998) as shown in Table (2).

Table (2): Some properties of the mineral fertilizer

\begin{tabular}{|l|c|c|c|c|c|c|}
\hline Fertilizer & Color & Grade & $\begin{array}{c}\text { Size of } \\
\text { granules, } \\
\text { cm }\end{array}$ & $\begin{array}{c}\text { Density, } \\
\mathbf{g} / \mathbf{c m}^{3}\end{array}$ & $\begin{array}{c}\text { Friction } \\
\text { angle, } \\
\text { degree }\end{array}$ & $\begin{array}{c}\text { Repose } \\
\text { angle, } \\
\text { degree }\end{array}$ \\
\hline Ammonium sulfate & $\begin{array}{c}\text { White } \\
\text { crystalline }\end{array}$ & $20.6 \% \mathrm{~N}$ & $0.08-0.19$ & 1.769 & 25.5 & 32 \\
\hline $\begin{array}{l}\text { Super phosphate } \\
\text { Calcium }\end{array}$ & $\begin{array}{c}\text { White } \\
\text { powder }\end{array}$ & $\begin{array}{c}15.5 \% \\
\mathrm{P}_{2} \mathrm{O}_{5}\end{array}$ & 0.036 & ---- & 31.45 & 43.3 \\
\hline
\end{tabular}

The fertilizers were used in three doses as follows :-

$1-" 40 \mathrm{~kg} / \mathrm{fed}$." of Super phosphate Calcium and $30 \mathrm{~kg} / \mathrm{fed}$. of Ammonium sulfate $\left(F_{1}\right)$

2-"60 kg fed." of Super phosphate Calcium and $50 \mathrm{~kg} / \mathrm{fed}$. of Ammonium sulfate $\left(\mathrm{F}_{2}\right)$.

3-"100 kg/fed." of Super phosphate Calcium and $75 \mathrm{~kg} / \mathrm{fed}$. of Ammonium sulfate (F3).

The application of Super phosphate Calcium was added after soil preparation and before seeding fore seed drill with a new furrow opener and at last stage of soil preparation fore another two of seedling methods but Ammonium sulfate was added during seeding for all methods. All application times of fertilizer were done according to the technical recommendation of the Ministry of Agriculture.

The seeding machines were adjusted while stationary to provide 60 $\mathrm{kg} / \mathrm{fed}$ of wheat seeds plus different rates of fertilizers under study, verified in the field at different speeds under study.

The time of the first plant was appeared through the soil. Observation were taken every day. The emergence rat was calculated as the percentage of emerging seedlings counted in $1 \mathrm{~m}$ sampling area at three replicates for each treatment at different times after seeding. Counted were made 3, 6, 9, $12,15,18,21$ and 24 days after seeding. The percentage of emergence was determined as the ratio between number of emerging seedlings counted at each time with respect to their final number (last observation date).

The viability coefficient " $\mathrm{C}_{\mathrm{v}}$ " was determined by calculating number of seeding per meter for furrow adjusted (Soza et al. , 1998). This coefficient is 
product of germination capacity and the visible damage of the seeding per meter at different seeding speed from the following equation (Soza et al. , 2004):-

$$
C_{v}=\frac{G C}{100} \times \frac{100-V B}{100}
$$

Where

$\mathrm{C}_{\mathrm{v}}$ : viability coefficient, GC: germination capacity, and VB: visible damage.

After germination (three weeks later) the numbers of plants through sides of the furrow center line in $10 \mathrm{~m}$ long were counted to fined out the scattering and uniformity distribution of seeds.

Seed depth was determined by excavating individual plants (coleoptiles and seed remnant intact) and measuring the distance between the chlorophyll frees stem and the seed remnant (Tessier et al. , 1989).

Plant samples were collected after 25, 45,75and100 days from seeding. Mean of 5 plants was taken for the determination of plant height $(\mathrm{cm} / \mathrm{plant})$

\section{RESULTS AND DISCUSSION}

\section{Sowing depth and uniformity of plant distribution}

Seed drill allowed seeds to be placed at the same depth in almost all field and study condition. The average seeding depth was $(3.4$ to $3.6 \mathrm{~cm})$ and $(2.9$ - $3.4 \mathrm{~cm}$ ) fore modified seed drill and seed drill respectively, not being significantly different. On the other hand the average spacing of plants in the row were $(2.6-2.8 \mathrm{~cm})$ and $(2.7-3.1 \mathrm{~cm})$ for modified seed drill and seed drill, the longitudinal distribution of plants per linear meter of furrow, show that the small discrepancy of plant spacing between different seed drills was the minimum possible, compatible with the adjustment variation of the seeders. This is may be due the to the good soil preparation and seeding forward speed within the limit as used by farmers, thus resulting in similar values of sowing depth and longitudinal distribution uniformity specially in the case of modified seed drill, the integrated seed deposition adjustment system associated with wing openers allowed improved accuracy in seeding depth and uniformity distribution. Finally, at least writhen the aim of this research, this different plant spacing and depth between seed drills could not have effected the study parameters.

Viability coefficient $\left(\mathrm{C}_{\mathrm{v}}\right)$ and germination capacity $(\mathrm{Gc})$

Table (3) show that variation in viability coefficient $\left(\mathrm{C}_{v}\right)$ and germination capacity (Gc) values for different treatments under study. The data rivaled that the some trend $C_{v}$ and $G c$ also the forward speed had slightly effect an $\mathrm{C}_{\mathrm{v}}$ and $\mathrm{Gc}$.

Results show that $\mathrm{C}_{\mathrm{v}}$ and $\mathrm{Gc}$ were slightly discovered with an increase in forward speed. This reduction was negligible in this study. This may be due to the small discrepancy of speed depth and spacing in furrow different forward speed.

From the data in Table (3) it is clean that, the $G c$ and $C_{v}$ were highly affected by the fertilizer doses and its added method (according to seeding 
method). The average values of germination capacity at three fertilizes doses with different seeding methods were calculated and illustrated in Fig. (3). It can be seen that the highest values of Gc were at (P1) and the poor values were at (P2). The highest values $(98.6$ and $98.2 \%)$ were obtained at P1F2 and P1F3., but the poor values (61\%) was obtained with P2f3. This may be due to with(P1) deep placement fertilizes can increase fertilizer are efficiency and is best suited for better seed germination. This results confirmed with Ojha (2008) and Abdul-Shakor et al. (1990).

Generally the highly percentage of crimination capacity were records at (P1) with fertilizer doses F2 and F3, on the other hand noticed that increasing fertilizer dose frame F2 to F3 had not effect in germination capacity this means that safe fertilizer about and in the same time increase germination capacity.

Table 3: The number of plant, variation in viability coefficient $\left(C_{v}\right)$ and germination capacity (Gc)

\begin{tabular}{|c|c|c|c|c|c|}
\hline \multicolumn{3}{|c|}{ Treatments } & $\begin{array}{l}\text { Number of } \\
\text { plant per } \mathrm{m}^{2}\end{array}$ & $\begin{array}{c}\text { Germination } \\
\text { capacity }\end{array}$ & $\begin{array}{c}\text { Viability } \\
\text { coefficient }\end{array}$ \\
\hline \multirow{9}{*}{ P1 } & \multirow{3}{*}{ S1 } & F1 & 245 & 87.5 & 0.870 \\
\hline & & F2 & 275 & 98.2 & 0.975 \\
\hline & & F3 & 276 & 98.6 & 0.979 \\
\hline & \multirow{3}{*}{ S2 } & F1 & 242 & 86.4 & 0.857 \\
\hline & & F2 & 272 & 91.1 & 0.964 \\
\hline & & F3 & 274 & 97.9 & 0.972 \\
\hline & \multirow{3}{*}{ S3 } & F1 & 237 & 84.6 & 0.840 \\
\hline & & F2 & 270 & 96.4 & 0.957 \\
\hline & & F3 & 271 & 96.8 & 0.960 \\
\hline \multirow{9}{*}{ P2 } & \multirow{3}{*}{ S1 } & F1 & 201 & 71.8 & 0.712 \\
\hline & & $\mathrm{F} 2$ & 195 & 69.6 & 0.690 \\
\hline & & F3 & 180 & 66.4 & 0.659 \\
\hline & \multirow{3}{*}{ S2 } & F1 & 200 & 71.4 & 0.709 \\
\hline & & F2 & 195 & 69.6 & 0.690 \\
\hline & & F3 & 177 & 64.3 & 0.639 \\
\hline & \multirow{3}{*}{ S3 } & F1 & 198 & 70.7 & 0.702 \\
\hline & & $\mathrm{F} 2$ & 191 & 68.2 & 0.677 \\
\hline & & F3 & 172 & 61.5 & 0.610 \\
\hline \multirow{9}{*}{ P3 } & \multirow{3}{*}{ S1 } & $\mathrm{F} 1$ & 215 & 76.8 & 0.762 \\
\hline & & $\mathrm{F} 2$ & 231 & 82.5 & 0.819 \\
\hline & & F3 & 245 & 87.5 & 0.868 \\
\hline & \multirow{3}{*}{ S2 } & F1 & 211 & 75.3 & 0.751 \\
\hline & & $\mathrm{F} 2$ & 223 & 79.3 & 0.790 \\
\hline & & F3 & 242 & 86.4 & 0.857 \\
\hline & \multirow{3}{*}{ S3 } & F1 & 208 & 74.3 & 0.737 \\
\hline & & F2 & 218 & 77.9 & 0.773 \\
\hline & & F3 & 236 & 84.3 & 0.837 \\
\hline
\end{tabular}




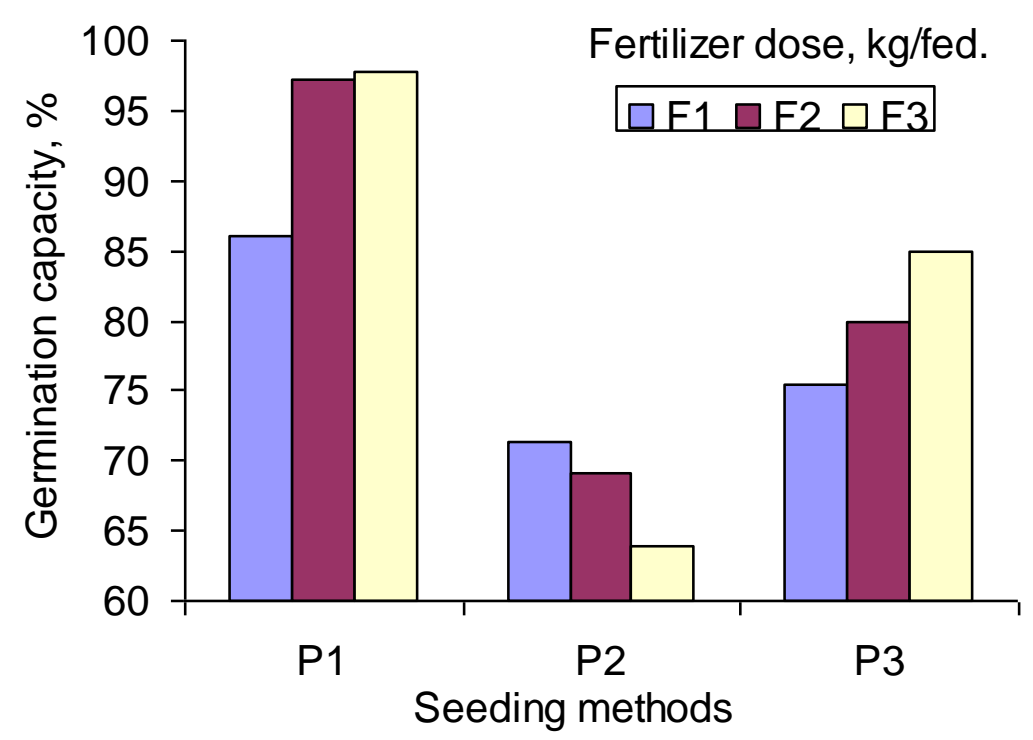

Fig. 3: The average values of germination capacity at three fertilizes doses with different seeding methods

\section{Plant emergence and population.}

The number of emerging seeding at different times after seeding and the percentage of emergence at each time for treatments and study were illustrated in figure (4) and (5). The results show that the emerging seeding was quicker and the emergence population higher for the seeding method (P1) compared with seeding methods P2 and P3.

Delayed emergence and poorer values of emergences population were observed with seeding method (P2). The values of emergence population and the percentage of emergence at 15 days after seeding were (230 plants $\mathrm{m} 1 \mathrm{~m} 2$ with $84.5 \%)$, (126 plants $\mathrm{m} 1 \mathrm{~m} 2$ with $64.9 . \%)$ and (173 plants $\mathrm{m} 1 \mathrm{~m} 2$ with $77.2 \%$ ) for $\mathrm{P} 1 \mathrm{~F} 2$ and $\mathrm{P} 3 \mathrm{~F} 2$ respectively this may be due to, the placement fertilizer is a good method to generalize the effects of fertilizer on emergence it can help in a achieving healthy germination, and extensive plant population which presumably led to the optimum crop yield. This results were agreed with Abdul-Shakour et al. (1990) and Ahmed et al (2004). On the other hand the conventional practice of seeding and fertilizer by seed drill results in seed damage and poor germination due to the toxic effect by close contact of fertilizer with seed, this not only delayed emergence but also reduced plant population and crop yield. With broadcast fertilizer(p3) the fertilizer not utilized by crop roots and losses by water drainage, finally increase the total need of fertilizer, consequently increase the population of soil and water. 
J. Agric. Sci. Mansoura Univ., 34 (5), May, 2009
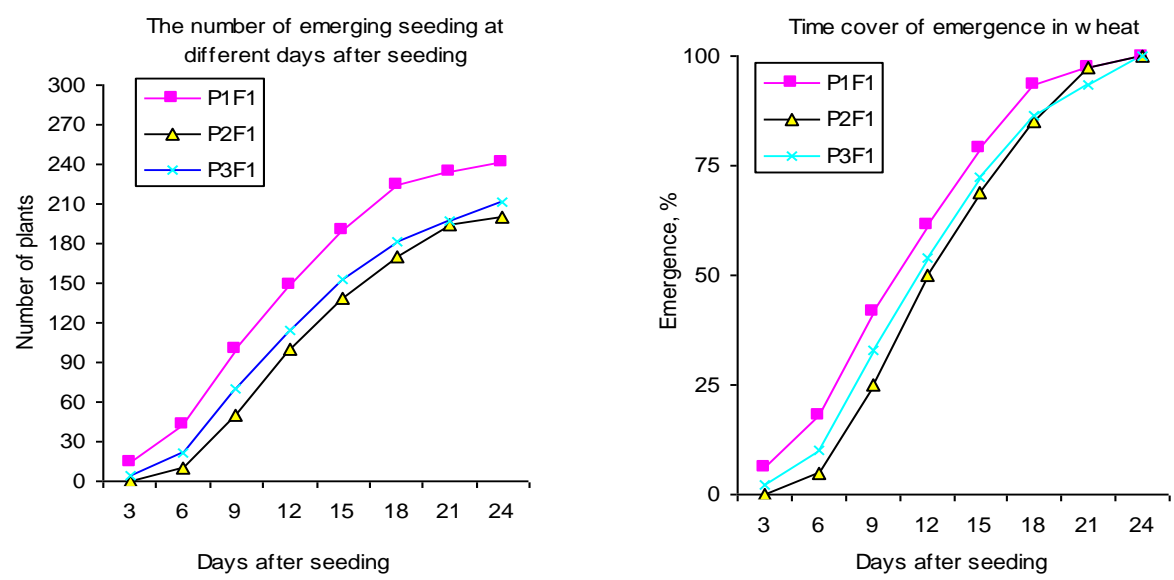

The number of emerging seeding at different day after seeding
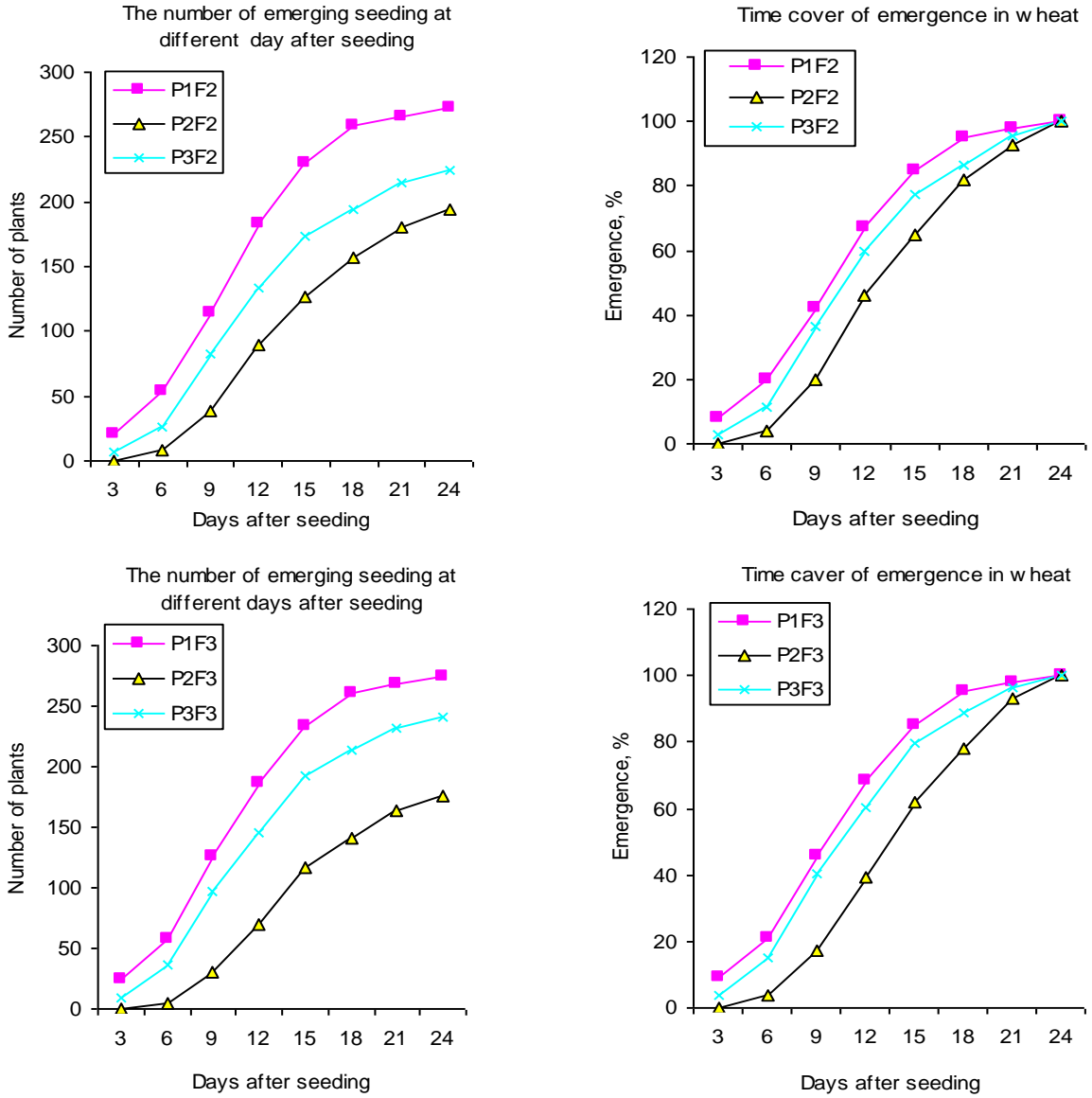

Fig. 4: The number of emerging seeding at different days.

Fig. 5: Time course of emergence. 


\section{The growth rate and plant height}

The effect of seeding methods (manner of fertilizer application) and fertilizer doses on the plant growth is plotted for all treatments in Table (4). Data revealed that, the height of wheat plants generally increased by deposition fertilizer sub seed level (P1). Results showed significant difference in plant height between seeding methods at the same period. On the other hand, at 100 days period, the highest wheat length was obtained with (P1F2 and P1F3).This trend is agreed with the time to emergence, and plant population, where as the less time to emergence and exclusive plant population the better condition. Better condition obtained for seeding by modified seed dill. This indicated that deposit fertilizer sub seed level gives better condition and is actually more availability of fertilizer that wheat plant takes up or need from the soil and which are required by the plant. Generally results show that at period 100 days the plant height was increased with modified seed drill (P1) by $43.8 \%$ and $19 \%$ with compared by(P2 and $\mathrm{P} 3$ ).

From the all previous results $t$ he modify seed dill is drills fertilizer and seed together but at different depths and covers seed and fertilizer thus improves germination, increased plant population and height. Finally it not only saves seeds and fertilizer but also supports optimum growth of plant.

Table 4: Plant height $(\mathrm{cm})$ at different period versus seeding method and fertilizers doses

\begin{tabular}{|c|c|c|c|c|c|}
\hline $\begin{array}{c}\text { Seeding } \\
\text { method }\end{array}$ & Fertilizer doses Days & $\mathbf{2 5}$ & $\mathbf{4 5}$ & $\mathbf{7 5}$ & $\mathbf{1 0 0}$ \\
\hline \multirow{3}{*}{ P1 } & F1 & 15 & 30 & 70 & 93 \\
\cline { 2 - 6 } & F2 & 13 & 40 & 84 & 103 \\
\hline \multirow{3}{*}{ P2 } & F3 & 20 & 43 & 90 & 105 \\
\cline { 2 - 5 } & F1 & 8 & 18 & 42 & 71 \\
\hline \multirow{3}{*}{ P3 } & F2 & 7 & 15 & 36 & 63 \\
\cline { 2 - 6 } & F3 & 6 & 14 & 30 & 59 \\
\cline { 2 - 6 } & F1 & 8 & 19 & 46 & 79 \\
\hline & F2 & 11 & 22 & 52 & 82 \\
\hline
\end{tabular}

\section{Conclusion}

The main results can be summarize as follow:

1- Forward speed slightly effect on study parameters.

2- The seed depth and uniformity distribution show the small discrepancy and could not have effected the study parameters.

3- The highest values of viability coefficient, germination capacity, early emergence, emergence ratio at different period, plant population and height were obtained with modified seed drill at (F2).

May be conclude that, the modified seed drill could result in 40 and $30 \%$ saving phosphates and nitrogen fertilizer respectively also increased plant population by 30 and $14 \%$ compared with seeding and applied fertilizer by seed drill (P2) and seeding by seed drill with broadcast fertilizer (P3). 


\section{REFERENCES}

Abdul Shakoor, Afzal T.M., Jandool K. (1990). Selection of seed-cum-fertilizer drill: Technical Considerations. Agricultural Mechanization in ASIA. Africa And Latin America, VOL. 21 NO.1. 35-39.

Adel-Wahab, M.K. and B.M. El-Bahrawy (1998). Prototype of fertilizer equipment used in citrus orchards. Miser, J. Agr. Eng.,15(3): 512-522.

Ahmed, M.; A. Rashid and A.A. Mirani (2004). Development and evaluation of fertilizer band placement drill for wheat. Journal of Engineering and Applied Sciences. Vol. 23(1): 41-49.

Bueno, J.; J.L. Hernandez; M. Alvarez; C. Amiama (2002). Seeding opener and fertilizer placement in no-tillage silage corn production. In: proceeding of the International Conference on Agricultural Engineering, vol.1 Budapest, Hungary, 30 June- 4 July, pp. 71-76.

Gupta, R.A.; P. Mohnot; M. Satsiyar; and R.B. Marvia (2004). Development and testing of a seed-cum-fertilizer drilling attachment to tractor-driven cultivator. Agricultural Mechanization in ASIA. Africa And Latin America, vol.35; No.2; Page.15-20.

Morrison, J.; III J. Hendrick and R. Schafer (1996). Soil forces on coulter and disc-opener combinations. T. ASAE, 39(2): 369-376.

Ojha, H. (2008). Seed cum fertilizer drill. north.gian.org/seed.

Richey, C.B. (1981). Innovations in planters and seeders. Ag. Eng. 62(2): 16-17.

Soza, E.; G. Botta; M. Tourn and R. Hidalgo (2004). Sowing efficiency of two seeding machines with different metering devices and distribution systems: a comparison using soybean, Glycine max (L) Merr. Spanish J. of Ag. Res., 2(3): 315-321.

Subudhi, C.R.; P.C. Pradhan and P.C. Senapati (1997). Seed drill for upland rice grown in undulating terrain. Dryland Ag. Res. Proj., Orissa Univ. of Ag. And Tec. (OUAT), Phulbani 762001, Orissa, India.

Tessier, S.; G.M. Hyde; R.I. Papendick and K.E. Saxton (1991). No-till seeders effects on seed zone properties and wheat emergence. T. ASAE, 34(3): 733-739.

Tice, E. and J. Hendrick (1991). Disc coulter forces: Evaluation of mathematical models. T. ASAE, 34(6): 2291-2298.

Tsegaye, T. and C.E. Mullins (1994). Effects of mechanical impedance on root growth and morphology of two varieties of pea (Pisum sativum L.). New Phytol. 126(4): 707-713.

Willatt, S.T. (1986). Root growth of winter barley in a soil compacted by the passage of tractors. Soil Till. Res. 7(1-2): 41-50. 
يهدف هذا البحث إلي تطوير أداء آلة التسطير لتقوم بتسطير البذور والسماد في عملية

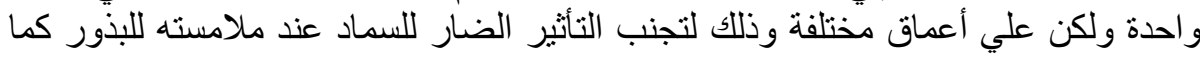

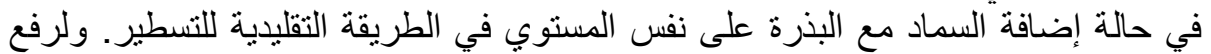

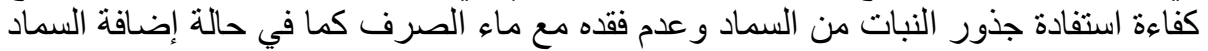

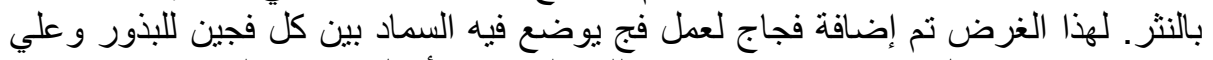

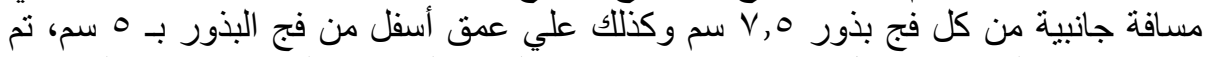

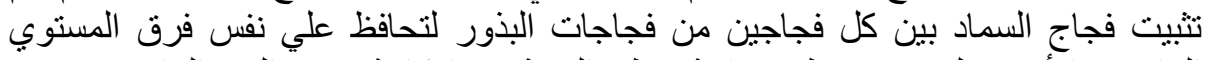

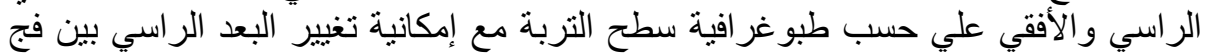

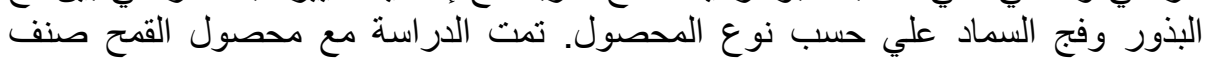

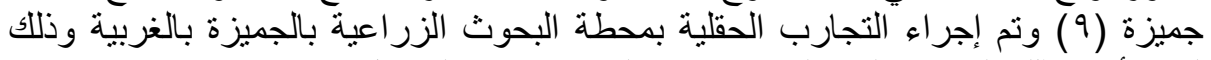

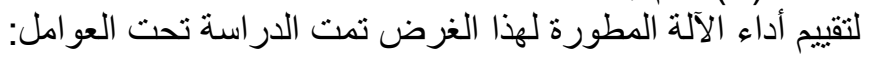

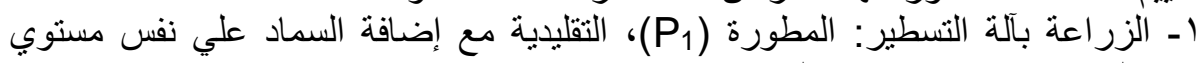

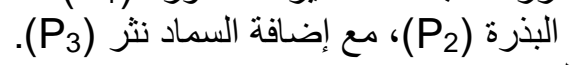

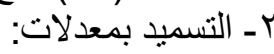

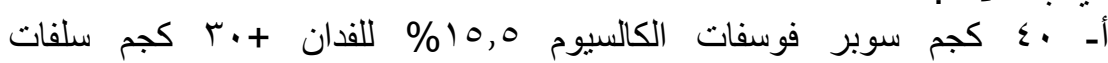

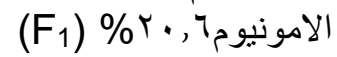

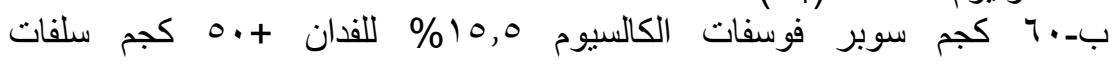

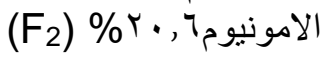

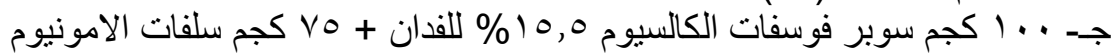

$\left(F_{3}\right) \% r^{\prime}, \tau$

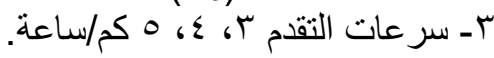

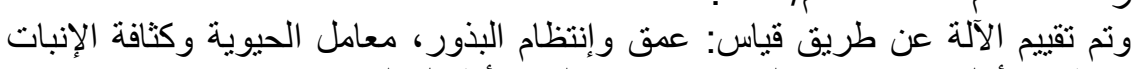

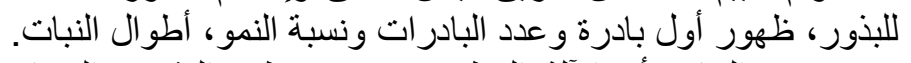

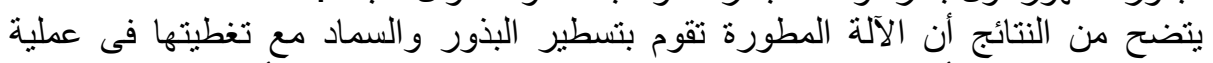

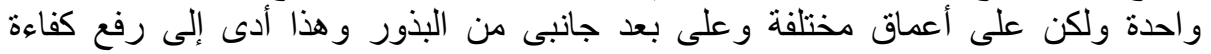

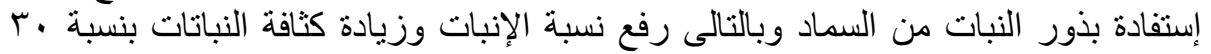

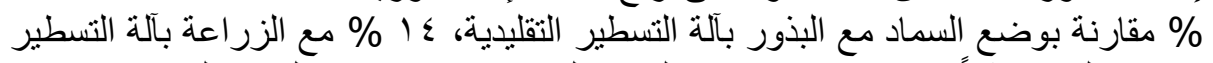

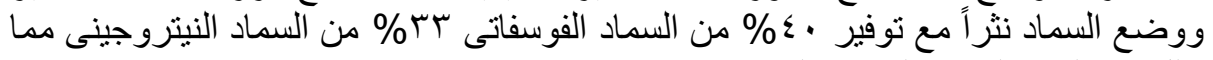

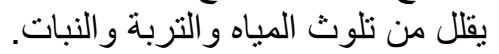

